\title{
CMEARTICLE \\ Clinics in diagnostic imaging (160)
}

Nor Lenny $\underline{A b d u l l a h}^{1}$, MBBS, FRCR, Swee Chye Quek ${ }^{2}$, MBBS, FRCPCH, Kar Yin Seto ${ }^{3}$, MBBS, FRCR, Lynette Li San $\underline{\text { Teo }}^{1}$, MBBS, FRCR

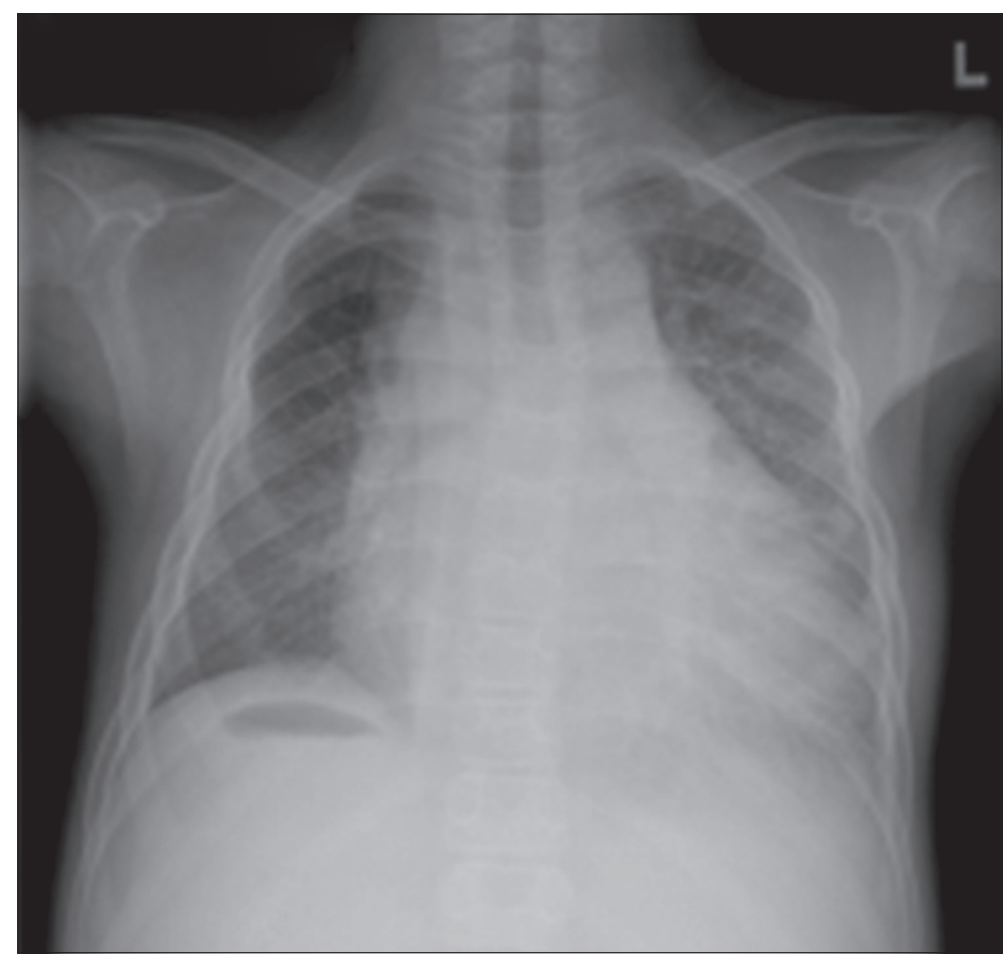

Fig. 1 Frontal chest radiograph of the patient.

\section{CLINICAL PRESENTATION}

A 13-year-old male patient on long-term follow-up for complex congenital heart disease at the paediatric cardiology unit presented with shortness of breath. He was born via elective lower section Caesarian section (LSCS) at 38 weeks due to the mother's two previous LSCSs. He had normal body weight and Apgar scores at birth. He was apparently well until Day 3 of life, where he was found to have a cardiac murmur prior to discharge. Echocardiography then showed complex congenital heart disease with a single ventricle, left-sided major aortopulmonary collaterals and pulmonary atresia. At two months of life, he was admitted for an elective right Blalock-Taussig (BT) shunt. A subsequent left BT shunt was performed at 20 months of age. Chest radiography was performed for the patient (Fig. 1). What does the radiograph show?

${ }^{1}$ Department of Diagnostic Imaging, ${ }^{2}$ Department of Paediatrics, National University Hospital, Singapore, ${ }^{3}$ Department of Radiology, Alexandra Hospital, Jurong Health Services, Singapore

Correspondence: Dr Lynette Li San Teo, Senior Consultant, Department of Diagnostic Imaging, National University Hospital, 1E Kent Ridge Road, NUHS Tower Block, Level 12, Singapore 119228. Iynette_Is_teo@nuhs.edu.sg 


\section{IMAGE INTERPRETATION}

The chest radiograph (Fig. 1) shows levocardia with gross cardiomegaly. The pulmonary vascular markings are minimally increased. The gastric bubble is seen on the right side. There is no gross pleural effusion.

\section{DIAGNOSIS}

Levocardia with abdominal situs inversus.

\section{CLINICAL COURSE}

By the time the patient was 13 years old, his left BT shunt was patent. However, the flow of the right BT shunt into the right pulmonary artery (RPA) was not well demonstrated on echocardiography, and the patient had developed poor effort tolerance. Early in the patient's life, it was decided that a longterm Fontan operation was deemed unsuitable, as he had nonconfluent pulmonary arteries on angiography and reconstruction may not be possible. Cardiovascular magnetic resonance imaging (CMR) was performed after echocardiography in order to better delineate the anatomy, and to quantify volumes and function. This was because further palliative surgery was considered given that the patient's average oxygen saturation level was $80 \%$ on room air. CMR demonstrated atrial situs inversus, right-sided univentricular atrioventricular connection, double outlet right ventricle, and single ventricle physiology with an outlet ventricular septal defect (Fig. 2). A right-sided aortic arch and bilateral superior vena cavae were present. There was also abdominal situs inversus. Following imaging workup, palliative surgery of an atrial septectomy and replacement of the RPA were performed a few months after presentation. After surgery, the patient improved clinically. Echocardiography also confirmed improved ventricular function, as compared to preoperative values. Post-surgery lung perfusion imaging showed no significant difference in differential perfusion between the two lungs.

The patient subsequently developed IgA nephropathy, which augmented his congestive cardiac failure. He had repeated admissions for decompensated congestive cardiac failure, but succumbed at the age of 17 years to end-stage heart failure secondary to complex congenital heart disease and IgA nephropathy with superimposed pneumonia.

\section{DISCUSSION}

Situs refers to the position of the atria (not the cardiac apex) and abdominal viscera relative to the midline. Levocardia, dextrocardia and mesocardia are general terms that indicate the position of only the cardiac apex and do not give any indication of the cardiac structure or abdominal situs.

Situs solitus is the normal arrangement of abdominal organs with levocardia (Fig. 3) and is associated with a less than $1 \%$ incidence of congenital heart disease. ${ }^{(1,2)}$ Situs inversus is a congenital condition in which the heart and abdominal organs are either reversed or mirrored from their normal positions, and is almost always associated with dextrocardia (Fig. 4). Patients with this condition have a $3 \%-5 \%$ incidence of congenital heart

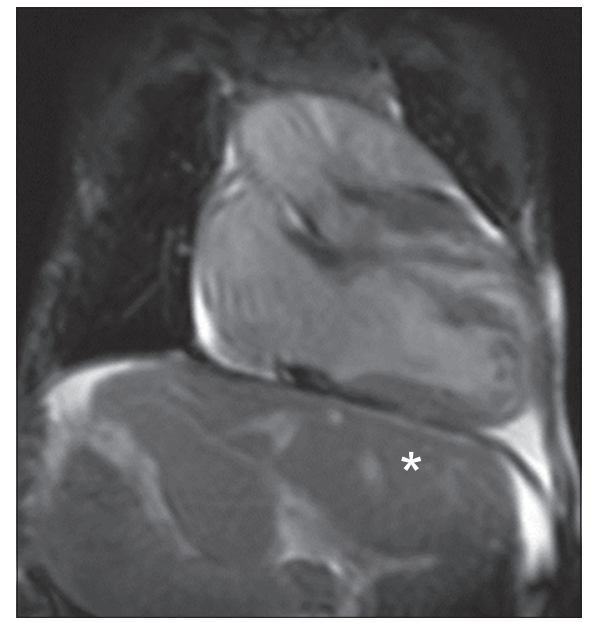

Fig. 2 Selected CMR still image from a cine coronal gradient-echo sequence of the heart and upper abdomen shows the presence of levocardia with abdominal situs inversus. The right lobe of the liver is seen below the left hemidiaphragm $\left({ }^{*}\right)$.

disease. ${ }^{(2)}$ A midline heart or mesocardia occurs either in situs solitus or rarely, in situs inversus (Fig. 5).

In situs ambiguous (situs indeterminatus or heterotaxia), there is abnormal arrangement of the organs and major blood vessels, which is different from that of situs solitus and situs inversus (Fig. 6). The stomach and liver are typically midline, with congenital heart disease occurring in $50 \%-100 \%$ of cases. ${ }^{(3)}$ Major subcategories of situs ambiguous include asplenia and polysplenia. ${ }^{(3)}$ Another form of cardiac malposition is the crisscross heart (Fig. 7). The criss-cross heart is an extremely rare anomaly, characterised by abnormal rotation of the ventricular mass along its major axis. It may be associated with any malformation of the heart segments and connections. Due to the complex structural changes and rarity of the anomaly, rotation of the ventricular axis is often misdiagnosed. The frequency of this condition is less than $8 / 1,000,000$ and accounts for less than $0.1 \%$ of congenital heart defects. ${ }^{(4)}$

Our patient had situs inversus, which is almost always associated with dextrocardia. Its association with levocardia where the cardiac apex is located in a normal position is extremely rare. ${ }^{(1)}$ Almost $100 \%$ of cases of situs inversus with levocardia are associated with congenital heart disease, ${ }^{(2)}$ most of which are severe or associated with asplenia or polysplenia syndromes, or situs ambiguous. ${ }^{(5)}$ Situs inversus with levocardia has a reported incidence of $1: 22,000$ in the general population and accounts for $0.4 \%-1.2 \%$ of all individuals with congenital heart diseases. ${ }^{(5)}$

The exact cause of situs inversus with levocardia is not fully understood. ${ }^{(5)}$ The condition can be identified or excluded via a thorough history and physical examination, chest radiography, electrocardiography and echocardiography. ${ }^{(6)}$ Depending on the initial examination findings, computed tomography (CT) or CMR may also be used. CT provides good anatomic detail for confirming visceral organ position, cardiac apical position, intracardiac anatomy and great vessel branching. CT, however, entails radiation, which should be avoided in the paediatric age group. CMR, which does not utilise ionising radiation, is the optimal imaging modality for confirming the above. 

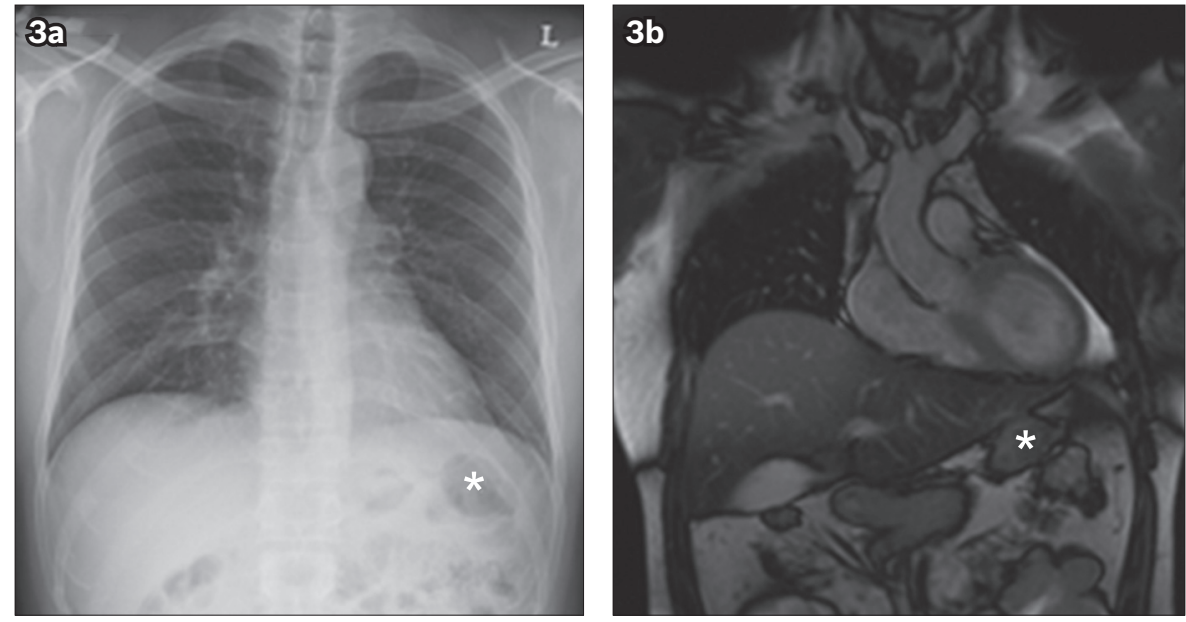

Fig. 3 (a) Conventional chest radiograph shows normal arrangement of the heart and abdominal organs. The stomach bubble $\left.{ }^{*}\right)$ is seen on the left upper quadrant and the liver on the right upper quadrant. (b) Corresponding image from a coronal localiser gradient-echo sequence CMR.
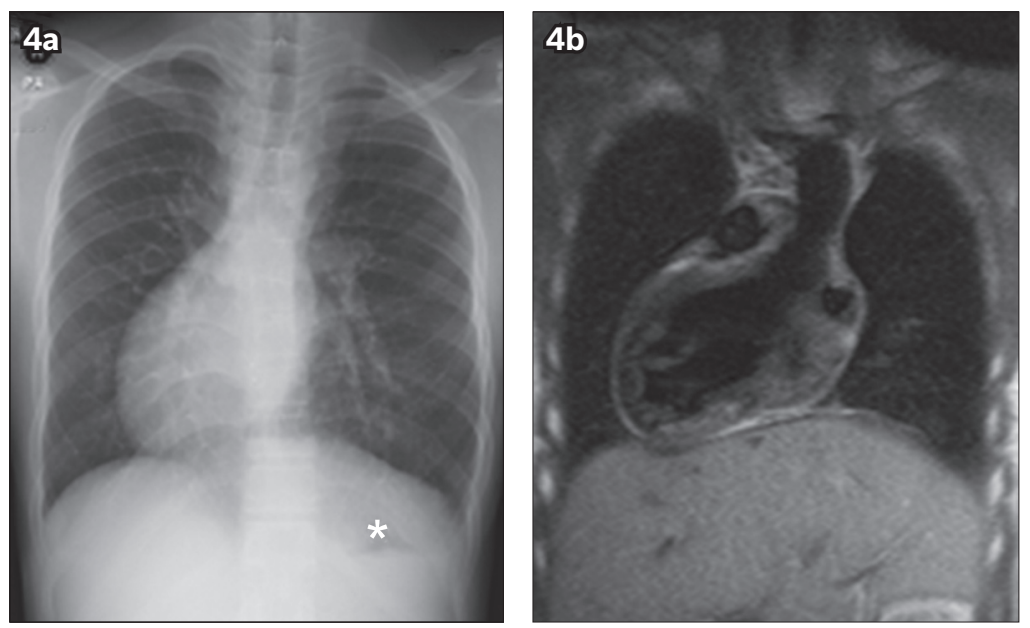

Fig. 4 (a) Chest radiograph shows dextrocardia with situs solitus, as evidenced by the stomach bubble $(*)$ located below the left hemidiaphragm. (b) Selected image from a coronal half-Fourier acquisition single-shot turbo spin-echo (HASTE) CMR confirms the diagnosis.
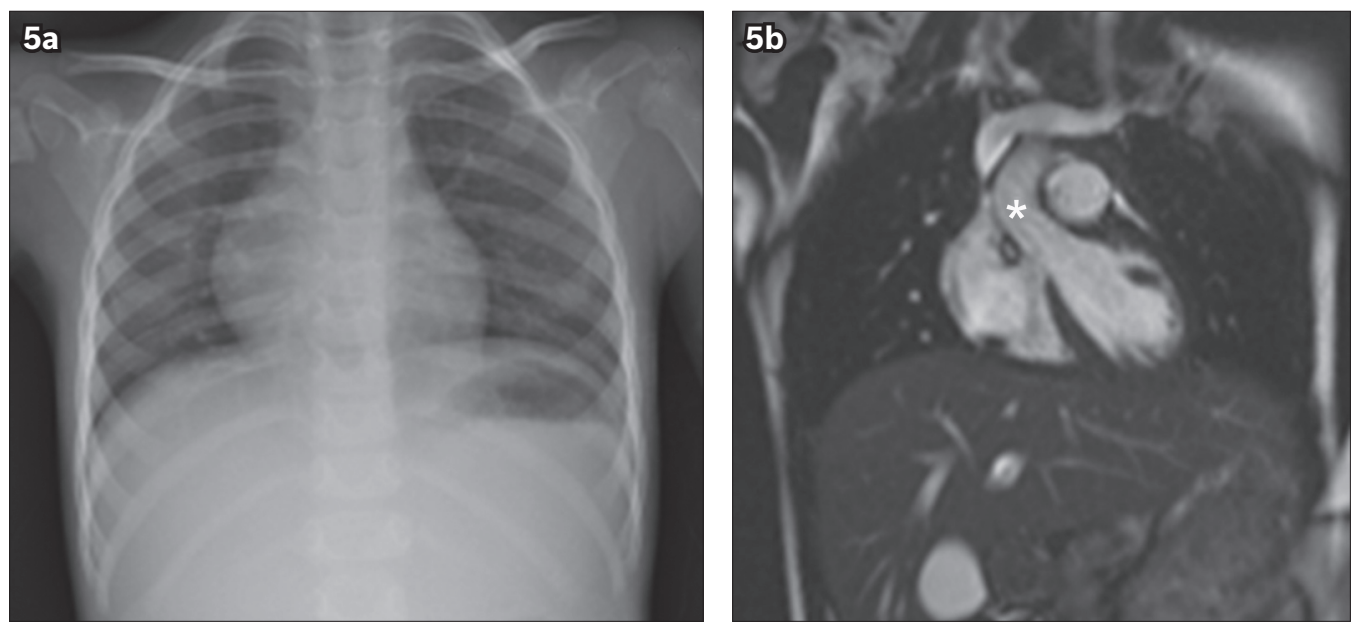

Fig. 5 (a) Chest radiograph of a 7-year-old girl shows midline cardiac position in the presence of thoracic and abdominal situs solitus. The cardiac silhouette extends equally to the right and left of midline. The cardiac silhouette is hump-shaped due to superimposition of the right atrium and right ventricle. (b) Selected image from a cine gradientecho left ventricular outflow tract view of the same patient confirms that the bulk of the cardiac mass is in the centre of the thorax. Normal position of the ascending aorta is noted $\left({ }^{*}\right)$. 

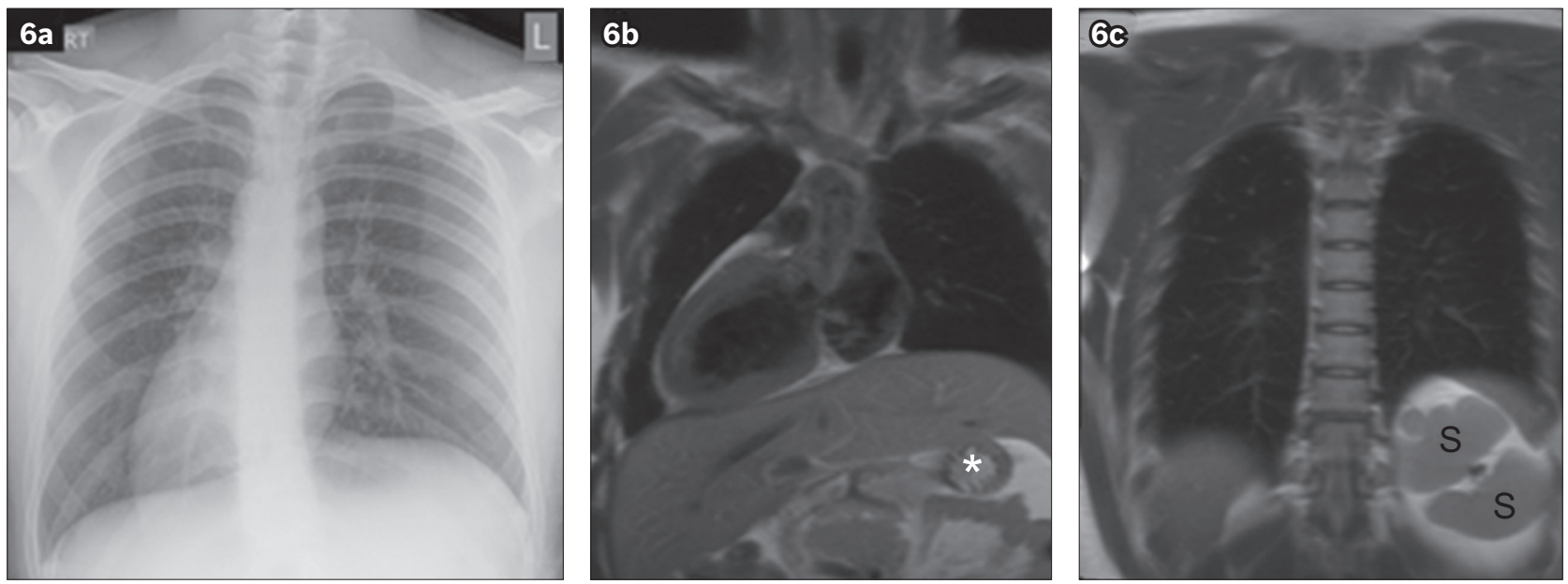

Fig. 6 (a) Chest radiograph shows dextrocardia. (b \& c) Selected images from a coronal HASTE sequence of the same patient show normal position of the liver and stomach bubble $\left({ }^{*}\right)$ with polysplenia (S).
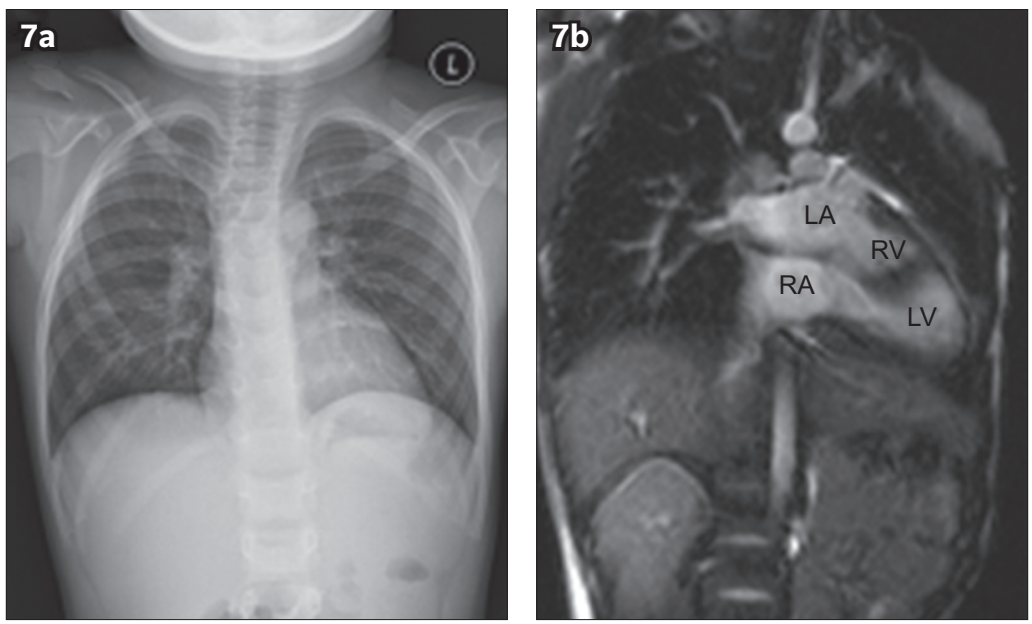

Fig. 7 (a) Conventional chest radiograph shows normal arrangement of the heart and abdominal organs. (b) Selected still image of the same patient from a coronal cine gradient-echo sequence shows the left atrium (LA) located superiorly to the right atrium (RA). LV: left ventricle; RV: right ventricle.

CMR is also the gold standard for determining cardiac volumes and function. ${ }^{(7-9)}$

The prognosis of situs inversus with levocardia is poor, and only $5 \%-13 \%$ of patients survive for more than five years, mainly due to the severity of an associated cardiac abnormality. ${ }^{(6)}$ It is important for clinicians to be aware of the fact that discordant

ABSTRACT Levocardia (left-sided cardiac apex) with abdominal situs inversus is extremely rare. This is also known as isolated levocardia and is almost always associated with severe forms of congenital heart defects with poor prognosis. We report isolated levocardia in a 13-year-old symptomatic male patient. The purpose of this paper is to outline the imaging features of isolated levocardia and to highlight the role of cardiovascular magnetic resonance imaging (CMR) in the diagnosis and management of such cases. Other forms of cardiac malposition, including dextrocardia, mesocardia and criss-cross heart, with chest radiograph and CMR correlation, are also discussed.

Keywords: cardiovascular magnetic resonance imaging, isolated levocardia, situs inversus cardiac shadows and stomach bubbles are usually found in association with severe abnormalities of the heart and major blood vessels. These imaging findings should prompt a thorough investigation for potential abnormalities. CMR is usually used for complex and difficult cases.

\section{REFERENCES}

1. Winer-Muram HT, Tonkin IL. The spectrum of heterotaxic syndromes. Radiol Clin North Am 1989; 27:1147-70.

2. Shucet IB. Normal and abnormal cardiac position (situs anomalies). In: The Ultrasound of Life [online]. Available at: http://www.fetalultrasound. com/online/text/7-004.HTM. Accessed July 30, 2014.

3. Fulcher AS, Turner MA. Abdominal manifestations of situs anomalies in adults. Radiographics 2002; 22:1439-56.

4. Taksande AM. Echocardiographic recognition of a criss-cross heart with double outlet right ventricle. Images Paediatr Cardiol 2013; 15:3-7.

5. Jo DS, Jung SS, Joo CU. A case of unusual visceral heterotaxy syndrome with isolated levocardia. Korean Circ J 2013; 43:705-9.

6. Vijayakumar V, Brandt T. Prolonged survival with isolated levocardia and situs inversus. Cleve Clin J Med 1991; 58:243-7.

7. Kashiwagi S, Ishikawa T, Onoda N, et al. Laparoscopic adrenalectomy in a patient with situs inversus. JSLS 2013; 17:487-90.

8. Bartram $\mathrm{U}$, Fischer $\mathrm{G}, \mathrm{Kramer} \mathrm{HH}$. Congenitally interrupted inferior vena cava without other features of the heterotaxy syndrome: report of 5 cases and characterization of a rare entity. Pediatr Dev Pathol 2008; 11:266-73.

9. Yoo SJ, Kim YM, Choe YH. Magnetic resonance imaging of complex congenital heart disease. Int J Card Imaging 1999; 15:151-60. 


\section{SINGAPORE MEDICAL COUNCIL CATEGORY 3B CME PROGRAMME} (Code SMJ 201504B)

Question 1. The following are features of situs inversus:

(a) Normal arrangement of abdominal organs with levocardia.

(b) The heart and abdominal organs are either reversed or mirrored from their normal positions.

(c) Congenital heart disease is present in approximately $20 \%$ of cases.

(d) Situs inversus is always associated with dextrocardia.

Question 2. The following are features of situs ambiguous:

(a) Abnormal arrangement of the organs and major blood vessels, which is different from that of situs solitus and situs inversus.

(b) Congenital heart disease occurs in $5 \%$ of cases.

(c) The stomach and liver are typically located in the right hypochondrium.

(d) Asplenia or polysplenia may be present.

Question 3. The following are features of criss-cross heart:

(a) It is an extremely common anomaly.

(b) It involves abnormal rotation of the atrial mass along its major axis.

(c) It involves abnormal rotation of the ventricular mass along its major axis.

(d) It may be associated with any malformation of the heart segments and connections.

Question 4. The following are features of isolated levocardia:

(a) Situs inversus with dextrocardia.

(b) The cardiac apex is in the normal position.

(c) Congenital heart disease occurs in almost $100 \%$ of cases.

(d) The prognosis is good.

Question 5. Regarding imaging in isolated levocardia:

(a) Computed tomography $(\mathrm{CT})$ can provide good anatomical detail for confirming visceral organ and cardiac apex positions.

(b) $\mathrm{CT}$ is the investigation of choice in the paediatric population.

(c) Cardiovascular magnetic resonance imaging (CMR) does not involve ionising radiation.

(d) CMR is the gold standard for cardiac volumes and function.

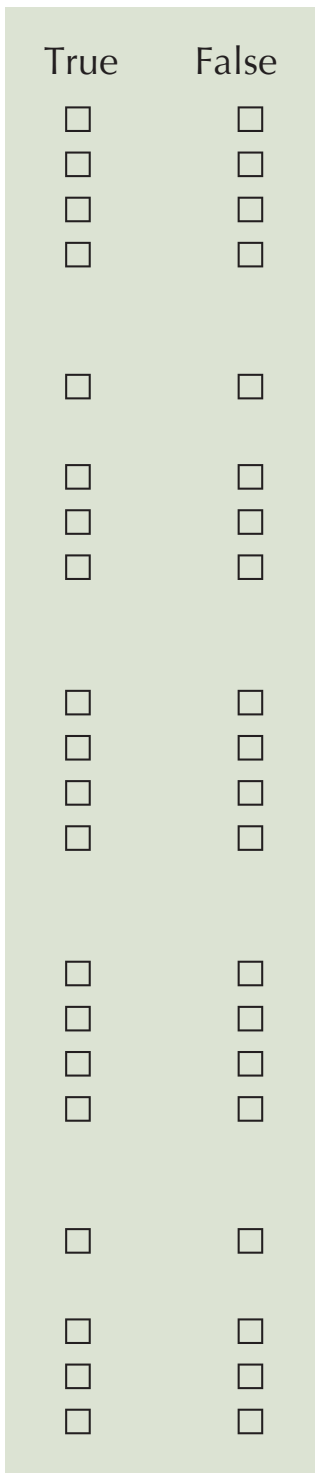

\section{Doctor's particulars:}

Name in full

MCR number

Email address

\section{SUBMISSION INSTRUCTIONS:}

(1) Log on at the SMJ website: http://www.sma.org.sg/publications/smjcurrentissue.aspx and select the appropriate set of questions. (2) Provide your name, email address and MCR number. (3) Select your answers and click "Submit".

\section{RESULTS:}

(1) Answers will be published in the SMJ June 2015 issue. (2) The MCR numbers of successful candidates will be posted online at the SMJ website by 5 June 2015. (3) Passing mark is $60 \%$. No mark will be deducted for incorrect answers. (4) The SMJ editorial office will submit the list of successful candidates to the Singapore Medical Council. (5) One CME point is awarded for successful candidates.

Deadline for submission: (April 2015 SMJ 3B CME programme): 12 noon, 29 May 2015. 